\title{
Undergraduate Surgical Education: a Global Perspective
}

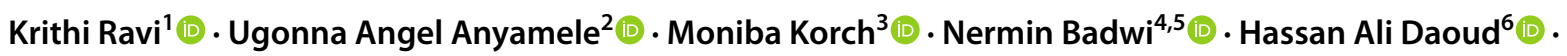 \\ Sayed Shah Nur Hussein Shah ${ }^{7}$ (1)
}

Received: 20 May 2021 / Accepted: 24 May 2021 /Published online: 22 June 2021

(c) Association of Surgeons of India 2021

\begin{abstract}
Undergraduate surgical education is failing to prepare medical students to care for patients with surgical conditions, and has been significantly compromised by the COVID-19 pandemic. We performed a literature review and undertook semi-structured reflections on the current state of undergraduate surgical education across five countries: Egypt, Morocco, Somaliland, Kenya, and the UK. The main barriers to surgical education at medical school identified were (1) the lack of standardised surgical curricula with mandatory learning objectives and (2) the inadequacy of human resources for surgical education. COVID-19 has exacerbated these challenges by depleting the pool of surgical educators and reducing access to learning opportunities in clinical environments. To address the global need for a larger surgical workforce, specific attention must be paid to improving undergraduate surgical education. Solutions proposed include the development of a standard surgical curriculum with learning outcomes appropriate for local needs, the incentivisation of surgical educators, the incorporation of targeted online and simulation teaching, and the use of technology.
\end{abstract}

Keywords Medical school $\cdot$ Undergraduate $\cdot$ Education $\cdot$ Training $\cdot$ Skills

\section{Introduction}

Clinical practice is seeing and hearing and doing and if we have decided that surgery is part of the curriculum then it can only be taught in relation to patients who are seen, examined and followed by the students.Professor Douglas Roy (1925-2003) [1]

Nermin Badwi, Hassan Ali Daoud and Sayed Shah Nur Hussein Shah contributed equally to this work.

\section{Krithi Ravi}

krithi.ravi@uhs.nhs.uk

1 Southampton General Hospital, University Hospital Southampton NHS Foundation Trust, Southampton, UK

2 School of Medicine, University of Leeds, Leeds, UK

3 Faculty of Medicine and Pharmacy of Marrakesh, University Cadi Ayyad, Marrakesh, Morocco

4 Faculty of Medicine, Zagazig University, Zagazig, Egypt

5 InciSioN Egypt, Zagazig, Egypt

6 School of Medicine, Amoud College of Health Sciences, Amoud University, Borama, Somaliland

7 Kiambu Referral Hospital, Kiambu, Kenya
The challenges and opportunities for undergraduate surgical education are captured by this quote from Professor Douglas Roy, who led three surgical departments across three continents during his career. It is important to marry theoretical and practical teaching, and to expose students to the entirety of the surgical care pathway, from the initial diagnosis; to the shared decision-making between the patient and the surgeon; and to pre-operative optimisation, surgical therapy, and postoperative care. This holistic overview is not only essential for aspiring surgeons, but also for future physicians and general practitioners who may be managing patients' long-term condition(s) and facilitating their postoperative recovery [2].

However, these learning needs are often unaddressed due to the gap between the theory that medical students are taught, and the limited opportunities they have to apply their theoretical learning. Furthermore, the lack of structure and support during surgical rotations [3] leads to decreased exposure to the surgical care pathway as a whole. This results in unfamiliarity with the overarching clinical principles of caring for patients with surgical conditions. Unsurprisingly, medical students report feeling less prepared for surgical placements and emergency surgery on-calls as trainee doctors, compared to medical placements and on-calls [4]. 
The authors of this paper are a group of medical students and junior doctors working and learning in different health systems in Egypt, Morocco, Somaliland, Kenya, and the United Kingdom (UK). We conducted an initial literature review using the PubMed database to identify available literature on the current state of surgical education in our respective countries. We discussed this literature and our lived experiences of surgical education to develop prompts for individual semi-structured reflections. The themes which emerged in our discussions and reflections form the basis of this article. In this article, we examine the main barriers to meaningful surgical education at the undergraduate level, consider the impact of the COVID-19 pandemic, and propose potential solutions to address these barriers.

\section{Challenges}

\section{Lack of Standardised Undergraduate Surgical Curricula and Learning Objectives}

Table 1 outlines the similarities and differences in surgical curricula, and teaching and assessment methods for surgical education across medical schools in Egypt, Morocco, Somaliland, Kenya, and the UK. Of these five countries, national guidelines for surgical education do not exist in three countries. For example, in the UK, the General Medical Council's latest standards for medical education and training, published in 2015, do not mention surgical training [5]. Some countries, such as Kenya, have central bodies which broadly outline the scope of undergraduate surgical education: the curriculum outlined by the Kenyan Medical Practitioners and Dentists Board specifically mentions key topics and skills within several surgical specialties including general surgery, orthopaedics, ophthalmology, and otolaryngology [6]. However, these curriculum requirements are not communicated directly to medical students; instead, students rely on individual departments within their specific medical schools to cover these topics. Furthermore, different medical schools in Kenya are affiliated with hospitals with differing levels of resources and infrastructure. Therefore, universities tied to small district hospitals may find it difficult to adequately expose their students to advanced surgical care, as well as to certain subspecialties. This may result in discrepancies in surgical education despite the availability of a standard surgical curriculum.

This lack of standardisation engenders several issues, which are discussed further below.

\section{Discrepancy Between Theoretical and Practical Learning}

Without standardised surgical curricula, medical schools are not held accountable for the surgical education they provide.
This leads to a lack of alignment between theoretical and practical learning objectives. A study of Moroccan medical students' experiences of learning about maxillofacial emergencies demonstrated that the correlation between theoretical learning in lectures and practical learning in the emergency room was only $27.5 \%$ [7]. Furthermore, due to the conventional structure of medical school teaching, anatomy is often taught at the beginning, with students being unable to observe anatomical principles being used in practice until their surgical rotations much later in their medical education (Table 1). Although medical students have consistently rated anatomy teaching as having high medical relevance [8], medical students in their clinical years report being less confident in their anatomical knowledge [9].

The reflections undertaken by the authors demonstrated a consistent disparity between the content and complexity of theoretical teaching and the limited opportunities to observe and apply these principles in practice. Practical learning opportunities are required to reinforce theoretical concepts, and to improve students' confidence with applying these concepts to patient care.

The undergraduate surgical curriculum covers surgery extensively in a way that could be overwhelming. Thus, there is a need to prioritize and focus on the topics most relevant to clinical practice and local needs, with general practitioners in mind.- NB, Egypt

\section{Overreliance on Student and Educator Motivation}

Secondly, in the absence of a mandatory surgical curriculum with learning objectives, medical students may believe that surgical education is less important. This belief may be perpetuated by a lack of assessment of surgical skills: Table 1 shows that in all the countries considered, standardised assessments of practical skills other than history-taking and clinical examination are absent or rare. Therefore, students may be tempted to focus on other topics that they consider more immediately relevant to their undergraduate education:

Even if the perfect opportunity arises for students who are not surgically-inclined to observe or participate in theatre, there is a sense of optionality about learning about surgery. I have seen students behave with the attitude, "This isn't for me, it's all so specialised, I don't have to be here - I would rather catch up on my respiratory notes instead"...For those who obtain exposure, are the experiences standardised? Is the learning useful, or are students simply observing procedures that they do not need to memorise at their undergraduate level? Perhaps this is what deters non-surgicallyinclined students - there is little drive to be in theatre, there is little drive to stay.-UAA, UK 


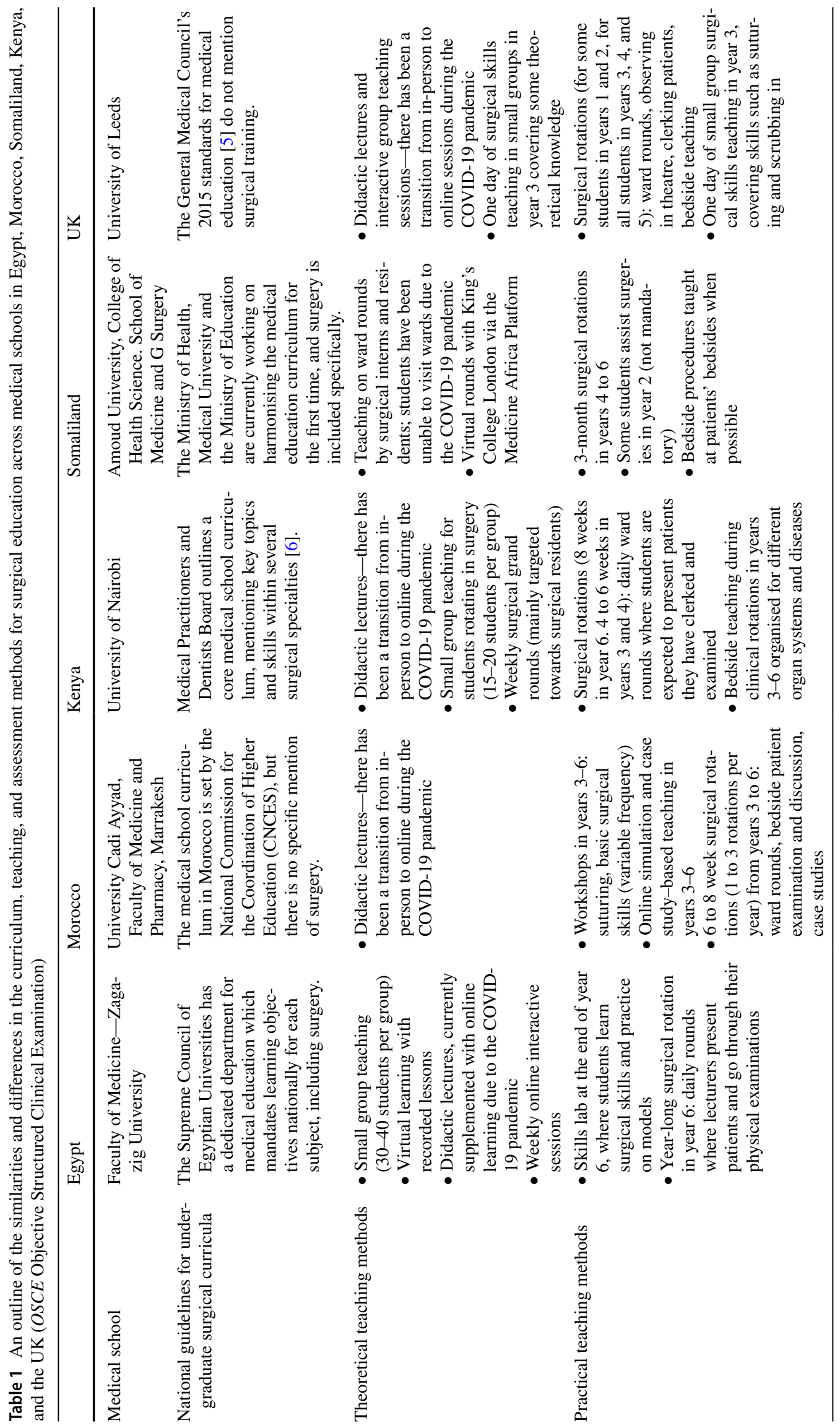




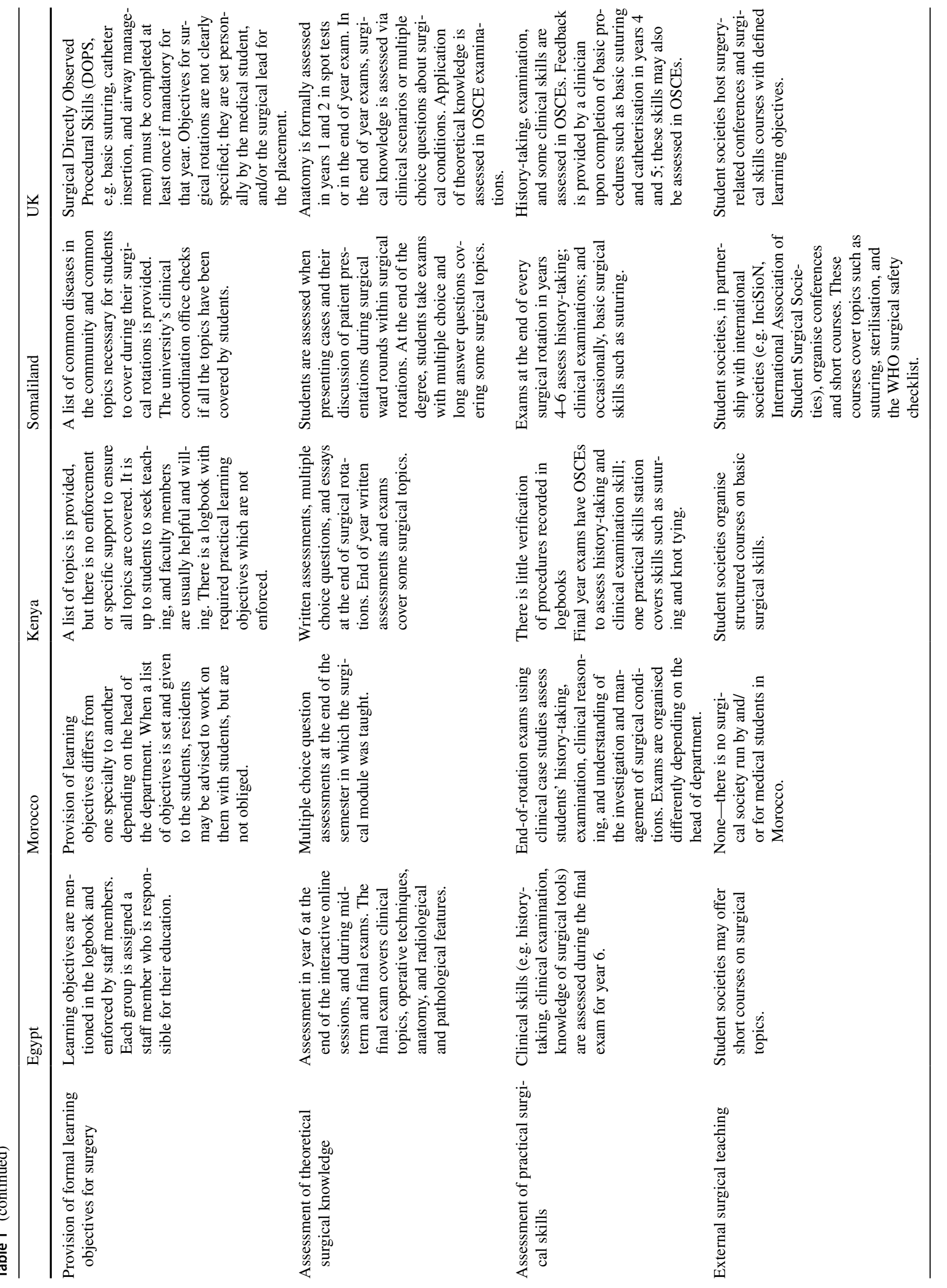


Even if students themselves are motivated, the quality of their surgical learning remains dependent on the attitude and motivation of educators without compulsory surgical learning outcomes. These issues are apparent when it comes to operating theatre-based learning. In addition to influencing students' career choices [10], medical students recognise that learning in theatres promotes knowledge retention and integration, enhances their ability to explain surgical procedures to patients, and is beneficial for their future roles as trainee doctors [11]. However, $43 \%$ of students in a survey at the University of Leeds reported negative experiences in the operating room [12]: students felt unwelcome, believed that staff had unrealistic expectations of their knowledge, and reported poor or inadequate learning experiences. A survey of UK medical students by Ravindra et al. [13] found that $80 \%$ of students believed attending theatres should be a mandatory course requirement, but self-reported attendance was low; students interested in surgery were significantly more likely to have attended more operating theatre opportunities than students who were undecided or not surgically inclined. A study of Australian medical students by Lyon showed that students found attending theatres to be more useful if they had specific learning objectives [11]. Overall, these studies support the need for structured surgical learning within clinical environments, particularly in operating theatres.

\section{Lack of Human Resources for Undergraduate Surgical Education}

Human resources are crucial for meaningful surgical education. Medical students consistently report that first-hand learning experiences with surgeons strongly influence their education. In the study by Lyon [11], there was a strong positive correlation between students' perceived usefulness of theatre learning and the willingness of senior surgeons and surgical registrars to teach them. Furthermore, surgical consultants and registrars have been shown to be important sources of positive and negative experiences during students' undergraduate years [10].

Unfortunately, the increasing clinical and academic commitments for surgeons leave little time for teaching [14]. This is especially true for surgeons working in low- and middle-income countries (LMICs) - in one survey of members of the Central, South, and East African College of Surgeons, the incidence of burnout was nearly $40 \%$ [15]. These commitments lead to less protected teaching time, with adverse consequences for surgical education. A Society of Academic and Research Surgery report [16] argues that surgical staff not attending timetabled teaching slots for medical students can lead to students misinterpreting this as an indication of disinterest or contempt.

In theatres, medical students are often "at the end of the training queue", with seniors prioritising more experienced postgraduate trainees instead [11]. Medical students who prove themselves to be worthy-through their knowledge, professional behaviour, willingness to help, and perseverance $[11,17]$ - are offered a place at the front of the "queue" as a "reward". However, even if they are allowed to scrub in, learning is hindered by limited engagement from surgeons focused on their case, a restricted view, and being relegated to "service provision" roles such as holding a retractor [3, 17]. Moreover, the practice of singling medical students out for such opportunities if they are deemed worthy risks contributing to exclusionary practices, whereby students from marginalised groups are granted fewer opportunities due to implicit bias [18].

Although medical students and new graduates may gain more theatre exposure in settings where they are considered an essential part of the workforce, adequate supervision is required to promote learning. A study of the preparedness of medical graduates for surgical internship in Kenyan district hospitals demonstrated a difference in expectations between the new graduates and their supervisors [19]: supervisors expected graduates to perform procedures independently after orientation, whereas graduates did not feel there was adequate supervision available when performing surgery. The study's authors suggest that this may be due to the heavy caseload in district hospitals compared to tertiary centres. In contrast, when Kenyan medical students doing their district hospital rotation were paired with consultants with a specific interest in medical education, they reported receiving more teaching on procedural skills compared to their rotation in a tertiary centre [20]. Therefore, the educational benefit of including medical students and new graduates as essential members of the surgical workforce appears to depend on the human resources available for supervision.

Outside of theatres, human resources continue to be essential in the provision of surgical teaching during ward rounds, which feature prominently in undergraduate surgical training across the world (Table 1). However, the learning derived from participating in ward rounds depends on the amount of time and energy that surgeons have to engage with medical students [21]. With expanding medical student cohorts and increasing numbers of students accompanying ward rounds [22], the effectiveness of ward round-based teaching is likely to be further reduced.

There is difficulty learning from shadowing and ward rounds due to limited time available for teaching, especially with increasing class sizes at medical school. Busy consultants result in students feeling "lost". A lack of guidance regarding how to approach clinicals results in confusion, and subsequent loss of interest.-SS, Kenya 


\section{Impact of COVID-19}

The COVID-19 pandemic has had a profound impact on undergraduate surgical education, exacerbating all the above challenges. Clinician redeployment to address the pandemic-related disease burden has been detrimental, particularly in areas where teaching methods are teachercentred. For instance, in Morocco, lectures represent 90\% of the academic teaching hours [23]. Medical schools have had to rapidly shift their teaching to online platforms, which has understandably affected the quality of teaching.

Medical students have had significantly reduced or no access to learning opportunities such as ward rounds and observing surgical procedures in theatre [24] (Table 1). This has widened the disparity between theoretical and practical learning. Even if medical students do have access to clinical learning environments, the marked decrease in operative caseload globally [25] further limits opportunities for surgical education at all levels of training. With postgraduate surgical trainees having difficulty completing the required number of procedures for their training [26], medical students are unlikely to be prioritised for surgical education in wards and theatres.

Finally, the impact of COVID-19-related burnout on surgical educators' availability and motivation to teach medical students should not be underestimated [27]. Even with the best intentions, the lack of time and the increased prevalence of exhaustion and depression amongst clinicians due to the unprecedented burden on healthcare systems will likely have adverse consequences for undergraduate surgical education.

\section{Solutions and Opportunities}

The marked variability in medical students' experiences of surgical education highlights the need for standardised national undergraduate surgical curricula with alignment of theoretical and practical learning objectives. These curricula need to be discussed with surgeons to ensure the training of a surgical workforce with skills appropriate for local needs. For instance, the Lancet Commission on Surgery has highlighted the lack of rural surgery rotations at medical school, and the effect this has on the density of surgical care providers in rural areas of LMICs [28]. The undergraduate surgical curriculum in Somaliland is an example of a curriculum which attempts to respond to local needs. Due to the paucity of healthcare workers in Somaliland [29], international partnerships have been established to address gaps in medical education. These partnerships deliver teaching to medical students on core topics, including surgery, with an emphasis on preparing graduates for practice [30]. Thus, a critical need to expand the healthcare workforce in Somaliland appears to have sharpened the focus on delivering undergraduate surgical teaching that is fit for purpose.

When changes to the surgical curriculum are implemented, their effects must be audited to ensure that any changes made are helpful, and to ensure that educational institutions are held accountable for the delivery of learning objectives [31]. If institutions demonstrate their commitment to delivering standardised surgical education, students are more likely to conceptualise surgery as an important part of their undergraduate medical education and engage with available learning opportunities.

The unique challenge of surgical education is the need to allow inexperienced medical students access to clinical learning environments, in which highly specialised skills are being practised, without compromising patient care. It is even more challenging to achieve this across an entire cohort of students. Therefore, medical schools should deliver standardised teaching to upskill medical students in certain key areas so that they can safely and effectively be exposed to surgical care in clinical environments. Previous studies have developed detailed recommendations for preparing medical students for theatre-based learning [11, 32]. These include a comprehensive orientation, briefing on theatre "etiquette", defined objectives for theatre-based learning with a focus on key procedures, and negotiation of a specific role for students in theatre. Medical students, even those without any surgical aspirations, should be acknowledged as legitimate learners in clinical settings, as facilitating understanding of the surgical care pathway is essential to optimising patient care.

Furthermore, medical schools' commitment to surgical education should be reflected in their investment in both the physical and human resources required for undergraduate surgical training. If new medical graduates are required to perform procedures such as skin suturing and wound debridement independently [19], basic surgical skills training needs to be delivered as part of the undergraduate curriculum. Even in settings where newly qualified doctors would not be expected to independently perform procedures, provision of surgical skills training would flatten the steep learning curve for postgraduate surgical trainees, and ensure that the playing field is more level. Hakim et al. found that $97 \%$ of UK medical students who responded to their survey felt practical surgical skills should be incorporated into the undergraduate curriculum [33]. Evidently, there is an appetite for surgical skills training amongst undergraduates.

Simulation training is highly valued by medical students when learning practical skills, and medical schools should endeavour to teach basic surgical skills using simulation wherever possible [34]. A Moroccan study found that $90 \%$ of medical student participants were confident about their ability to transfer the suturing skills they learned via simulation 
to their clinical practice [35]. The cost-effectiveness of simulation training is important to ensure equal availability of learning opportunities across medical schools. However, the cost of simulation teaching need not be prohibitive, with several low-fidelity bench models available for basic surgical skills training [36]. The intensive human resource requirement for simulation training also needs to be considered when increasing access to simulation training. For example, even though most medical schools in Morocco have been recently equipped with Medical Simulation Labs, their use is limited by the lack of trained teachers [23]. This issue may be addressed by sponsoring student surgical societies [32] and enabling near-peer teaching, with "training the trainer" courses to promote sustainability. In the UK, Kenya, Egypt, and Somaliland, student societies organise basic surgical skills and conferences, liaising with surgeons in their local institutions and international organisations to address gaps in undergraduate surgical education (Table 1).

There has been an explosion in the availability of remote learning resources since the advent of the COVID-19 pandemic, but these resources cannot be treated as a panacea. Generic online lectures on topics without explicit links to the medical school's surgical learning objectives may result in students perceiving their teaching as being irrelevant to their studies and disengaging. However, online learning offers specific opportunities to make surgical education more engaging and clinically relevant. A collaboration between Zagazig University's Surgery Department and EMLE Notes has eased the transition to online learning and allowed the surgical curriculum to be delivered through concise and engaging video lectures with graphics and audiovisual tools as opposed to text [37]. Furthermore, video recordings of surgical procedures with surgeons offering a step-by-step overview of the procedures may enable students to appreciate the intra-operative relevance of anatomy [3]. In the UK, online preparatory materials and targeted video lectures improved students' engagement with surgical bedside teaching [38], thereby increasing the yield from bedside teaching for both students and busy surgical educators.

There is a danger of losing out on the valuable interaction between students and surgical mentors with remote learning. However, successful efforts have been undertaken to preserve the interactive aspect of remote surgical education. In Morocco, an interactive compact disc (CD) has been developed to take students through common pathologies in general paediatric surgery, allowing them to navigate clinical cases by answering a series of questions [39]. This "problem-based learning" approach represents an effective way to align theoretical and practical learning, especially when it comes to low-frequency, high-stakes surgical emergencies that medical students may not come across during their undergraduate training.
Virtual reality (VR) and augmented reality (AR) also hold great promise for remote surgical education, particularly with COVID-19 social distancing requirements [40]. Although there are technical challenges which may limit the use of VR and AR in low-resource settings, the VR industry appears to be addressing these obstacles and reducing the cost of devices [41]. Scalpel 2.0, a virtual teaching programme led by Stanford Medicine, has already piloted the use of VR headsets for anatomy teaching in Kenya [42]. However, to ensure continued benefit for LMIC medical students, particular attention should be paid to the sustainability of collaborations which deliver VR and AR teaching in LMICs.

Lastly, the teaching role of surgeons and postgraduate surgical trainees requires increased prioritisation and incentivisation. Surgical teaching time should be protected, and specific teaching roles delegated and appropriately incentivised. A study in Scotland demonstrated a marked improvement in student learning during the post-take surgical ward round with support from Clinical Teaching Fellows [21]. Surgeons' involvement in medical education should be actively supported with targeted training in medical education, to ensure that surgical teaching is appropriate and relevant. As an example, in Somaliland, the "Prepared for Practice" partnership has trained over 100 academics in health education skills such as student-centred teaching, assessment, and curriculum development as part of the efforts to strengthen medical education [43]. Surgical trainers' contributions to medical education should be valued on par with their research contributions, and specific career progression pathways should be designed for surgeons who are interested in medical education.

\section{Conclusion}

Despite most medical graduates worldwide gaining the dual qualifications of Bachelor of Medicine and Bachelor of Surgery, the equal weighting given to the latter does not appear to reflect the current state of undergraduate surgical education. The COVID-19 pandemic has caused further disruption to surgical training in medical schools. In view of the need to train a surgical workforce to address the global burden of surgical disease, it is time for a renewed focus on surgical training in medical schools. Medical schools need to invest in the physical and human resources required to deliver a standardised surgical curriculum that responds to local needs. After all, this represents an investment in the surgeons of the future, and in the physicians and general practitioners who will be delivering patient care along the surgical care pathway. 
Author Contribution KR recruited the collaborating authors, coordinated the literature review, designed the semi-structured reflections, led the discussions, and wrote the manuscript. UAA and MK contributed to the literature review. UAA, MK, NB, SS, and HAD took part in the discussions and wrote semi-structured reflections. All authors read and approved the final version of the manuscript.

Data Availability Not applicable.

Code Availability Not applicable.

\section{Declarations}

Ethics Approval Not applicable.

Consent to Participate Not applicable.

Consent for Publication Not applicable.

Competing Interests The authors declare no competing interests.

\section{References}

1. Roy AD (1972) The role of the department of surgery in planning the undergraduate curriculum in the University of Nairobi. Langenbecks Arch Chir 332:587-590. https://doi.org/10.1007/bf012 82697

2. RCSEngland. National undergraduate curriculum in surgery. from https://www.rcseng.ac.uk/careers-in-surgery/careers-suppo rt/national-undergraduate-curriculum-in-surgery/. Accessed 19 May 2021.

3. Manzar A (2020) A new age for undergraduate surgical teaching. Postgrad Med J. https://doi.org/10.1136/postgradme dj-2020-138770

4. Lee MJ, Drake TM, Malik TA et al (2016) Has the bachelor of surgery left medical school?-a national undergraduate assessment. J Surg Educ 73(4):655-659. https://doi.org/10.1016/j.jsurg.2016. 01.005

5. GMC. (2015). Promoting excellence: standards for medical education and training.

6. Board, M. P. A. D. Bachelor of medicine and bachelor of surgery core curriculum. From https://kmpdc.go.ke/resources/mbchb.pdf. Accessed 19 May 2021.

7. El Abdli I (2018) L'impact du site de stage: Box de chirurgie Maxillo-faciale aux urgences sur la formation de l'étudiant (Doctor of Medicine). Retrieved from http://wd.fmpm.uca.ma/biblio/ theses/annee-htm/FT/2018/these225-18.pdf. Accessed 19 May 2021.

8. Pabst R (2009) Anatomy curriculum for medical students: what can be learned for future curricula from evaluations and questionnaires completed by students, anatomists and clinicians in different countries? Ann Anat 191(6):541-546. https://doi.org/10. 1016/j.aanat.2009.08.007

9. Farey JE, Bui DT, Townsend D, Sureshkumar P, Carr S, Roberts $C$ (2018) Predictors of confidence in anatomy knowledge for work as a junior doctor: a national survey of Australian medical students. BMC Med Educ 18(1):174. https://doi.org/10.1186/ s12909-018-1280-5
10. Ek EW, Ek ET, Mackay SD (2005) Undergraduate experience of surgical teaching and its influence and its influence on career choice. ANZ J Surg 75(8):713-718. https://doi.org/10.1111/j. 1445-2197.2005.03500.x

11. Lyon PM (2003) Making the most of learning in the operating theatre: student strategies and curricular initiatives. Med Educ 37(8):680-688. https://doi.org/10.1046/j.1365-2923.2003.01583.x

12. Chapman SJ, Hakeem AR, Marangoni G, Raj Prasad K (2013) How can we enhance undergraduate medical training in the operating room? A survey of student attitudes and opinions. J Surg Educ 70(3): 326-333. https://doi.org/10.1016/j.jsurg.2013. 01.008

13. Ravindra P, Fitzgerald JE, Bhangu A, Maxwell-Armstrong CA (2013) Quantifying factors influencing operating theater teaching, participation, and learning opportunities for medical students in surgery. J Surg Educ 70(4):495-501. https://doi.org/10.1016/j. jsurg.2013.02.011

14. Taylor I (2003) Surgery in the UK Undergraduate Curriculum. Surgery 21(5): I-II.

15. Commander SJ, Ellis D, Williamson H et al (2020) Predictors of burnout and depression in surgeons practicing in East, Central, and Southern Africa. J Surg Res 255:536-548. https://doi.org/10. 1016/j.jss.2020.04.038

16. Taylor, I., Reed, M., Kingsnorth, A., Carlson, G., \& Leaper, D. (2010). Surgery in the undergraduate curriculum: Society of Academic and Research Surgery.

17. Cope A (2010) The pedagogy of the operating theatre. (Doctor of Philosophy), Imperial College London. Retrieved from https:// core.ac.uk/download/pdf/76988674.pdf. Accessed 19 May 2021.

18. RCSEngland (2021) from https://www.rcseng.ac.uk/about-thercs/about-our-mission/diversity-review-2021/. Accessed 19 May 2021.

19. Muthaura PN, Khamis T, Ahmed M, Hussain SR (2015) Perceptions of the preparedness of medical graduates for internship responsibilities in district hospitals in Kenya: a qualitative study. BMC Med Educ 15:178. https://doi.org/10.1186/ s12909-015-0463-6

20. Kibore MW, Daniels JA, Child MJ et al (2014) Kenyan medical student and consultant experiences in a pilot decentralized training program at the University of Nairobi. Educ Health (Abingdon) 27(2):170-176. https://doi.org/10.4103/1357-6283.143778

21. Force J, Thomas I, Buckley F (2014) Reviving post-take surgical ward round teaching. Clin Teach 11(2):109-115. https://doi.org/ $10.1111 /$ tct. 12071

22. Maurice NM (2013) The scope of medical education in Egypt. World J Med Edu Res 3(1):22-26

23. Fourtassi M, Abda N, Bentata Y, Hajjioui A (2020) Medical education in Morocco: current situation and future challenges. Med Teach 42(9):973-979. https://doi.org/10.1080/0142159x.2020. 1779921

24. Khan S, Mian A (2020) Medical education: COVID-19 and surgery. Br J Surg 107(8):e269. https://doi.org/10.1002/bjs.11740

25. (2020) Elective surgery cancellations due to the COVID-19 pandemic: global predictive modelling to inform surgical recovery plans. Br J Surg 107(11), 1440-1449. https://doi.org/10.1002/bjs. 11746

26. Munro C, Burke J, Allum W, Mortensen N (2021) Covid-19 leaves surgical training in crisis. BMJ 372:n659. https://doi.org/10.1136/ bmj.n659

27. Adibe B (2021) COVID-19 and clinician wellbeing: challenges and opportunities. Lancet Public Health 6(3):e141-e142. https:// doi.org/10.1016/s2468-2667(21)00028-1

28. Meara JG, Leather AJ, Hagander L et al (2015) Global Surgery 2030: evidence and solutions for achieving health, welfare, and economic development. Lancet 386(9993):569-624. https://doi. org/10.1016/s0140-6736(15)60160-x 
29. Dahir S, Cotache-Condor CF, Concepcion T et al (2020) Interpreting the Lancet surgical indicators in Somaliland: a cross-sectional study. BMJ Open 10(12):e042968. https://doi.org/10.1136/bmjop en-2020-042968

30. King's College London. Prepared for practice. From https://www. kcl.ac.uk/research/prepared-for-practice. Accessed 19 May 2021.

31. Agha, R. A., Papanikitas, A., Baum, M., \& Benjamin, I. S. The teaching of surgery in the undergraduate curriculum. Part II-importance and recommendations for change. Int J Surg, 3(2), 151-157. (2005). https://doi.org/10.1016/j.ijsu.2005.03.016.

32. Khan $S$ (2020) Inspiring the next generation of surgeons. Postgrad Med J 96(1133):162-164. https://doi.org/10.1136/postgradme dj-2019-137281

33. Hakim MA, Dominguez ED, Priest S et al (2019) Surgical skills workshops should be a part of the United Kingdom undergraduate medical curriculum. Cureus 11(5):e4642. https://doi.org/10.7759/ cureus. 4642

34. Theodoulou I, Nicolaides M, Athanasiou T, Papalois A, Sideris M (2018) Simulation-based learning strategies to teach undergraduate students basic surgical skills: a systematic review. J Surg Educ 75(5):1374-1388. https://doi.org/10.1016/j.jsurg.2018.01.013

35. Shabi I (2019) Etude pédagogique et procédurale et formation de l'étudiant dans la prise en charge des plaies faciales. (Doctorat en Médecine), Faculté de Médecine et de Pharmacie, Marrakech

36. Denadai R, Saad-Hossne R, Todelo AP, Kirylko L, Souto LR (2014) Low-fidelity bench models for basic surgical skills training during undergraduate medical education. Rev Col Bras Cir 41(2):137-145. https://doi.org/10.1590/s0100-699120140002000 12

37. From https://gate.ahram.org.eg/News/2099139.aspx. Accessed 19 May 2021

38. Baker RC, Spence RA, Boohan M et al (2015) A novel approach to improve undergraduate surgical teaching. Ulster Med J 84(1):30-36
39. Ahlam A (2919) Conception d'un CD-ROM interactif destiné à la prise en charge des principales urgences viscérales pédiatriques. (Doctorat en Medicine), Faculté de Médecine et de Pharmacie Marrakech. Retrieved from http://wd.fmpm.uca.ma/biblio/theses/ annee-htm/FT/2019/these129-19.pdf. Accessed 19 May 2021.

40. Luck J, Gosling N, Saour S (2021) Undergraduate surgical education during COVID-19: could augmented reality provide a solution? Br J Surg 108(3):e129-e130. https://doi.org/10.1093/bjs/ znaa159

41. Muinga N, Paton C (2019) Virtual reality for medical and nursing training in low- and middle-income countries Pathways for Prosperity Commission Background Paper Series: Blavatnik School of Government, University of Oxford

42. Erickson M (2020) Educators will use virtual reality to teach anatomy. From https://med.stanford.edu/news/all-news/2020/10/educa tors-will-use-virtual-reality-to-teach-anatomy.html. Accessed 19 May 2021.

43. SPHEIR (2020) Preparing medical students for clinical practice: how health educators from the UK and Somaliland are transforming Somaliland's health education system. From https://www. spheir.org.uk/blog/preparing-medical-students-clinical-practicehow-health-educators-uk-and-somaliland-are. Accessed 19 May 2021.

Publisher's Note Springer Nature remains neutral with regard to jurisdictional claims in published maps and institutional affiliations. 